\title{
Postoperative Hypertension: Novel Opportunities in the Treatment of a Common Complication
}

Pasquale Sansone*, Maria Caterina Pace, Maria Beatrice Passavanti, Vincenzo Pota, Alessandro Tavano and Caterina Aurilio

Department of Anesthesiological, Surgical and Emergency Sciences - Second University of Naples, Naples, Italy

*Corresponding author: Pasquale Sansone, Professor, Department of Anesthesiological, Surgical and Emergency Sciences - Second University of Naples, Naples, P.zza Miraglia n.2; 80138, Italy, Tel: +39(0)815665180; Fax: 081-5665213; E-mail: pasquale.sansone@unina2.it

Received date: Febraury 27, 2015, Accepted date: July 10, 2015, Published date: July 17, 2015

Copyright: ( 2015 Sansone $\mathrm{P}$, et al. This is an open-access article distributed under the terms of the Creative Commons Attribution License, which permits unrestricted use, distribution, and reproduction in any medium, provided the original author and source are credited.

\begin{abstract}
Acute Postoperative Hypertension (APH) is one of the most common complications detected after surgery. It is a condition associated to a great number of causes and a pathophysiology still unclear which recognizes a central role in sympathetic activation. For these reasons, an ideal agent for treating APH does not exist, but we have to choose the most appropriate therapeutic strategy based on the individual case. We have reviewed some of the most important available treatments.
\end{abstract}

Keywords: Arterial hypertension; Postoperative

\section{Introduction}

High blood pressure is one of the most common diseases in the world's wide. It is estimated that, between 2009 and 2010, the prevalence of arterial hypertension reached about $28.6 \%$ of the US population over 18 years old [1]. Furthermore about $25 \%$ of patients in treatment for arterial hypertension undergoing surgery have showed perioperative complications [2]. In 2011 an EURO-Stat study revealed, on a sample of 791 patients (mean age 69 years, 30\% women), that about $29 \%$ had hypertensive perioperative complications and of this percentage, about $59 \%$ had a history of hypertension. Regarding the surgery, $40 \%$ of the patients having complications were subjected to cardiac surgery, while the remaining $60 \%$ are most distributed between gastrointestinal (17\%), orthopedic (11\%) and vascular (9.2\%) surgery [3]. Among perioperative complications, acute postoperative hypertension $(\mathrm{APH})$ is the most frequent one. This complication has an incidence ranging between 4 and 30\%, both cardiac and noncardiac surgery. It is defined by values of Systolic Hypertension $>190$ $\mathrm{mmHg}$ with or without a Diastolic blood pressure $\geq 100 \mathrm{mmHg}$ in, at least, two consecutive measurements, reported in the post- surgery time. The APH that occurs is manifested in the first 20 minutes of the postoperative period and lasts an average of 3 hours [4]. If it is left untreated, the APH is a major risk factor for adverse events such as postoperative bleeding, cerebrovascular damage, myocardial ischemia, arrhythmias, myocardial failure with congestive pulmonary edema, breakup of vascular anastomoses.

\section{Pathophysiology}

The pathophysiologic mechanism underlying APH is depending by patient's general condition, surgery and anesthesia. The most common $\mathrm{APH}$ risk factor, is a lack of preoperative intake of antihypertensive drugs scheduled, in patients already suffering from chronic arterial hypertension. Additional conditions favoring the hemodynamic instability are: massive infusion of fluids in perioperative time and all the conditions of physical stress generating an overactive Sympathetic system (hypoxia, anxiety, pain, etc.) [4]. It is important to check each one ofthe agents that may determine APH before starting a specific drug therapy but this choice is in any case necessary in the case of hypertensive emergency (coexistence of organ damage and critical pressure rise). In this case, the therapeutic purpose must be a reduction of mean arterial blood pressure by no more than $25 \%$. Another approach is to achieve a target of $10-15 \%$ reduction in dyastolic blood pressure or a value of $110 \mathrm{mmHg}$ of this parameter to reach in 30-60 min. Whatever the cause, it seems that a central role is represented by the activation of the sympathetic nervous system, as evidenced by elevated plasma catecholamine concentrations in patients with APH [5]. Sympathetic and parasympathetic nervous system activity and/or vasopressin release are the major mechanisms by which the CNS influences blood pressure. In this regard, current antihypertensive agents mayact at the sites responsible for blood pressure control in the CNS to decrease sympathetic outflow. Sympathetic activation may lead to renin-angiotensin system activation with the consequentially production of angiotensin II, proinflammatory cytokines (as interleukin-6) and sodium retention.

The final result is a peripheral vasoconstriction with an increase in afterload, SBP and DBP with or without tachycardia [6]. A severe elevations of the blood pressure is involved in a mechanical stress with endothelial injury. This increases endothelial permeability, actives the coagulation cascade, the platelets and leads to deposition of fibrin. The final result is a fibrinoid necrosis of the arterioles ensue generating a new production of vasoactive mediators [7].

\section{Therapy}

To solve an APH, several pharmacological solutions turned out to be efficient.

Alfa2- agonists: The hypotensive activity of this class of drugs, of which the most represented are the clonidine and dexmedetomidine, is developed through a reduction in the frequency and cardiac output due to central inhibition of sympathetic tone and increased vagal activity. This central mechanism also appears to be mediated by agonist activity on receptors imidazoline I1 $[8,9]$. Such a central effectresults in a better cardiovascular and endocrine response to surgical stimulation and the laryngoscopy. 
Besides hypotension, this class of drugs is able to determine a reduction of the FC and the consumption of oxygen, thereby obtaining a cardioprotective action. In 1997, Taittonen [10] evaluated (as comparing with placebo) clonidine and dexmedetomidine given intramuscularly in pre-medication; reduce the value of the SAP of approximately $11 \%$ and the DAP one of approximately $15 \%$. Clonidine also showed a hypotensive activity and heart rate-preserved even in the postoperative period (mean time to surgery: $76.5 \mathrm{~min}$ for the group associated with dexmedetomidine; $60 \mathrm{~min}$. For the group associated with clonidine). This difference is due to an increased half-life of clonidine (about $8.5 \mathrm{~h}$ ) compared with dexmedetomidine (approximately 4 hours). The authors found a reduction of Perioperative Oxygen Consumption $\left(\mathrm{VO}_{2}\right)$, the Carbon Dioxide Production $\left(\mathrm{VCO}_{2}\right)$ and the Energy Expenditure (EE), which ismore evident in the preoperative time. The $\mathrm{SpO}_{2}$ value showed no change for both types of drugs [10].

Additional effects associated with these drugs are: sedation, anxiolysis, reduction of the need for anesthetic agents during surgery, analgesia (if administered parenterally, epidural or intrathecal) $[5,11]$. The development of dexmedetomidine has been of particular interest, as it has a greater selectivity for the $\alpha 2$ adrenergic receptor (8-10 times greater than clonidine) and, consequently, a reduced activity a1-AR mediated and a low affinity for muscarinic, dopaminergic, serotonergic and $\beta$-adrenergic receptors. The more selective $\alpha 2-A R$, resulting in increased vagal activity and vasodilatation [7]. The most frequently observed adverse reactions were hypotension, hypertension and bradycardia. Particular care must be observed in the administration of dexmedetomidine in geriatric patients [12].

\section{Clonidine}

Dosage: $150 \mu \mathrm{g}$

Onset: $30 \mathrm{~min}$.

Duration: $4-6 \mathrm{~h}$

\section{Fenoldopam}

This drug acts as a dopamine receptor agonist $\mathrm{d}-1$. Its hypotensive action is determined by the vasodilatation of the renal arteries and by a direct action on the distal tubules, with inhibition of sodium reabsorption and an increase of its excretion [13]. Its activity on the renal excretion, makes it particularly useful in the treatment of patients with dysfunction of this body.

The most important adverse reactions are represented by reflex tachycardia and increased intraocular pressure, you must therefore avoid administration to patients suffering from myocardial ischemia, intra cranial hypertension and glaucoma [8].

\section{Fenoldopam}

Dosage: Initially $0.1 \mu \mathrm{g} / \mathrm{kg} / \mathrm{min}$, titrate by $0.05-0.1 \mu \mathrm{g} / \mathrm{kg} / \mathrm{min}$ every $15 \mathrm{~min}$ to maximum of $1.6 \mu \mathrm{g} / \mathrm{kg} / \mathrm{min}$.

Onset: $5 \mathrm{~min}$

Duration: $30-60 \mathrm{~min}$

\section{Clevidipine}

The clevidipine is a dihydropyridinic calcium channel blocker of the acting as selective arteriolar vasodilator, consequently it has not activity on preload. Peripheral resistances are reduced through the block of the L-type calcium channels and the consequent relaxation of smooth muscle cells of the arteriolar wall. Its very short half-life (about 1 minute) associated with a duration of action ranging from 5 to 15 minutes is particularly important, which allows tight control by the operator. The clevidipine is metabolized by esterases of RBCs, allowing safe use in patients with liver disease. Patients with a known hypersensitivity to eggs or soya, however, cannot take this medicine [9]. In addition to lowering blood pressure, the clevidipine increases coronary blood flow, stroke volume and cardiac output. It turns out to be effective in treating patients suffering from kidney disease and, at least in animal models, to protect against the risk of myocardial ischemia and reperfusion injury.

The study ECLIPSE, published in 2008, evaluating the outcomes of 1512 patients undergoing cardiac surgery and treated for APH; showed a reduction in mortality in the group treated with clevidipine than the group treated with nitroprusside. Proved a more effective therapeutical effect than both nitroprusside that nitroglycerin [1]. Another trial published in the same year, called ESCAPE-2, showed as Clevidipine rappresent a safe drug in treatment of acute postoperative hypertension after cardiac surgery $(91.8 \%$ of treatment success rate on 110 patients, without clinically significant increase in heart rate from baseline neither significant complications) [14]. In the 2010 the VELOCITY trial, a study enrolled 126 patients (of which 19 affected by acute heart failure) with systolic blood pressure $>180 \mathrm{mmHg}$; showed the efficacy and safely of Clevidipine in the treatment of patients with severe hypertension and acute heart failure [15].

\section{Clevidipine}

Dosage: Initially $2 \mathrm{mg} / \mathrm{h}$, doubled every $3 \mathrm{~min}$; not to exceed 132 $\mathrm{mg} / \mathrm{h}$

Onset: $2-4 \mathrm{~min}$

Duration: 5-15 min

\section{Nicardipine}

The Nicardipine is a calcium channel blocker of the second generation of the dihydropyridinic type. It is able to reduce blood pressure through a mechanism of peripheral, coronary and cerebralvasodilation. In this way it is able to reduce the damage from myocardial and cerebral ischaemia. In particular, the choice of Nicardipine is particularly useful in the treatment of ischemic stroke associated with a diastolic blood pressure greater than $120 \mathrm{mmHg}$ and / or a systolic blood pressure greater than $220 \mathrm{mmHg}$. It has no effect on the frequency and determines an increase of cardiac output [15]. The CLUE trial, a multicenter randomized clinical trial, enrolled 226 patients with systolic blood pressure of $180 \mathrm{mmHg}$ or more on two consecutive readings, Nicardipine reached more often the target range than Labetalol (expecially within 30 minutes) with less effect on the heart rate [12]. In a RCT study conducted on 40 patients, published in 2015, Bebawy [2] demonstrated the superiority of Nicardipine (success rate of 95\%) compared to Esmololo (success rate of 45\%), in the management of Postcraniotomy Emergence Hypertension (PCEH). In general, their results, agree with the hypothesis that the nicardipine-mediated vasodilation in the cerebral circulation, does not have a significant clinical impact reguarding itsadvantageous effects [2]. The duration of action of Nicardipine is initially short (10-15 min.). But its half-life increases significantly after $24 \mathrm{~h}$. 


\section{Nicardipine}

Dosage: Initially $5 \mathrm{mg} / \mathrm{h}$, increase to $2.5 \mathrm{mg} / \mathrm{h}$ every $5 \mathrm{~min}$ to maximum of $15 \mathrm{mg} / \mathrm{h}$

Onset: 5-15 $\mathrm{min}$

Duration: $4-6 \mathrm{~h}$

\section{Esmolol}

It is a drug belonging to the class of $\beta$-blockers, and it is characterized by its selective action on adrenergic cardiac $\beta 1$. Its duration of action is very short $(<30$ minutes after prolonged continuous infusion), being determined by non-specific plasma esterases. It can therefore be used with extreme maneuverability and it is not contraindicated in the presence of liver or kidney diseases, presenting instead a prolongation of action in patients with anemia. On a clinical level, the Esmolol has a chronotropic and inotropic negative effect, with the result of reducing the atrial pressure and cardiac output. Its use is contraindicated in patients with chronic obstructive pulmonary disease, asthma, bradycardia, patients taking other $\beta$-blockers and patients with heart failure.

\section{Esmolol}

Dosage: $500-1,000 \mu \mathrm{g} / \mathrm{kg}$ loading bolus within $1 \mathrm{~min}$, infusion at 50 $\mu \mathrm{g} / \mathrm{kg} / \mathrm{min}$, increasing by $25 \mu \mathrm{g} / \mathrm{kg} / \mathrm{min}$ every $10-20 \mathrm{~min}$ to maximum of $300 \mu \mathrm{g} / \mathrm{kg} / \mathrm{min}$

Onset: $60 \mathrm{~s}$

Duration: $10-20 \mathrm{~min}$

\section{Labetalol}

It is a selective $\alpha 1$ - and a non-selective $\beta$-adrenergic blocker at the same time. It is metabolized by the liver and it has a duration of action of up to four hours that justifies the difficulty to titrate labetalol as a continuous infusion. However, bolus injections of $1-2 \mathrm{mg} / \mathrm{kg}$ should be avoided as they produce sharp decreases in blood pressure $[13,15]$. Labetalol reduces systemic vascular resistance maintaining cerebral, renal, and coronary blood flow and the cardiac output, but heart rate may decrease due to its $\beta$-blocking effects. Labetalol should not be used in patients with severe sinus bradycardia, asthma, and heart blocks, but it is reported safely for patients undergoing to vascular, cardiac and intracranial surgical procedures [4]. In addition, labetalol can be safely administered during pregnancy [9].

\section{Labetalol}

Dosage: 20 -mg initial bolus, $20-80-\mathrm{mg}$ repeat boluses

Onset: $2-5 \mathrm{~min}$

Duration: $6 \mathrm{~h}$

\section{Nitroglycerin}

It is a potent venodilator that determines a hypotensive effect through the reduction in preload and cardiac output. An arterial effect is possible only at high doses. For this, nitroglycerin causes a reduction in left ventricular end-diastolic volume and pressure and reduces myocardial oxygen demand. Therefore, also thanks to an effect of coronary arteries dilatation, it is recommended for patients affected by hypertension associated with acute coronary insuficiency and it is not recommended for use in volume-depleted patients, or in those in whom cardiac output is preload dependent. It is also very useful in case of acute pulmonary oedema, but, in other conditions it is not recommended as a single primary blood pressure control agent due to its unpredictability to reduce blood pressure, the induction of a reflex tachycardia exacerbated by volume depletion, the early onset of tachyphylaxis (about 4 hours) and the formation of methemoglobinaemia after a prolonged use $[6,16]$.

\section{Nitroglycerin}

Dosage: $5 \mu \mathrm{g} / \mathrm{min}$, titrated by $5 \mu \mathrm{g} / \mathrm{min}$ every $5-10 \mathrm{~min}$ to maximum of $60 \mu \mathrm{g} / \mathrm{min}$

\section{Onset: $2-5 \mathrm{~min}$}

Duration: 3-5 min

\section{Conclusion}

The postoperative hypertension is a frequent complication that recognizes a multifactorialgenesis. Precisely for this reason, there is not a drug able to ensure all the features necessary to treat quickly and safely all forms of hypertension on any type of patient. Each drug should be chosen as close as possible to the patient characteristics, preexisting pathology and surgery.

\section{References:}

1. Aronson S, Dyke CM, Stierer KA, Levy JH, Cheung AT, et al. (2008) The ECLIPSE trials: comparative studies of clevidipine to nytroglicerin, sodium nitroprusside and nicardipine for acute hypertension treatment in cardiac surgery patients. Anesth Analg 107: 1110-1121.

2. Bebawy JE, Houston CC, Kosky JL, Badri AM, Hemmer LB, et al. (2015) Nicardipine is Superior to Esmolol for the Management of Postcraniotomy Emergence Hypertension: A Randomized Open-Label Study. 120: 186-191.

3. Piper MA, Evans CV, Burda BU, Margolis KL, O’Connor E (2014) Screening for High Blood Pressure in Adults: A Systematic Evidence Review for the U.S. Preventive Services Task Force. Agency for Healthcare Research and Quality, Report No.: 13-05194-EF-1.

4. Erstad BL, Barletta JF (2000) Treatment of hypertension in the perioperative patient. Ann Pharmacother 34: 66-79.

5. Fukushima K (1996) Central effect of epidurally admistered dexmedetomidine on sympathetic activity and postoperative pain in man. 82: S121.

6. Investigators PC (2002) Intravenous nesiritide vs nitroglycerin for treatment of decompensated congestive heart failure: a randomized controlled Trial. Publication Committee for the VMAC Investigators (Vasodilatation in the Management of Acute CHF) 287: 1531-1540.

7. Kamibayashi T, Maze M (2000) Clinical Uses of a2-Adrenergic Agonists. Anesthesiology 93: 1345-1349.

8. Lien SF, Bisognano JD (2012) Perioperative Hypertension: Defining AtRisk Patients and Their Management. Curr Hypertens Rep 14: 432-441.

9. Marik PE, Varon J (2009) Perioperative hypertension: a review of current and emerging. 21: 200-209.

10. Taittonen MT, Kirvelä OA, Aantaa R, Kanto JH (1997) Effect of clonidine and dexmedetomidine premedication on perioperative oxygen consumption and haemodynamic state. Br J Anaesth 78: 400-406.

11. Racle JP, Benkhadra A, Poy JY, Gleizal B (1987) Prolongation of isobaric bupivacaine spinal anestesia with epinephrine for hip surgery in the elderly. Anesth Analg 66: 442-446.

12. Naaz S, Ozair E (2014) Dexmedetomidine in Current Anaesthesia Practice- A Review. J Clin Diagn Res 8: GE01-GE04. 
Citation: Sansone P, Pace MC, Passavanti MB, Pota V, Tavano A, et al. (2015) Postoperative Hypertension: Novel Opportunities in the Treatment of a Common Complication. J Hypertens 4: 202. doi:10.4172/2167-1095.1000202

Page 4 of 4

13. Varon J, Marik PE (2011) Perioperative hypertension: Diagnosis and Treatment. Vasc Health Risk Manag 15: 143-148.

14. Singla N, Warltier DC, Gandhi SD, Lumb PD, Sladen RN, et al. (2008) Tretment of acute postoperative hypertension in cardiac surgery patients: an effecacy study of clevidipine assessing its postoperative antihypertensive effect in cardiac surgery-2 (ESCAPE), a randomized, double-blind, placebo-controlled trial. Anesth Analg 107: 59-67.
15. Peacock F 4th, Varon J, Ebrahimi R, Dunbar L, Pollack CV Jr (2010) Clevidipine for Severe Hpertension in Acute Heart Failure: A Velocity Trial Analysis. Congest Heart Fail. 16: 55-59.

16. Wilson DJ, Wallin JD, Vlachakis ND, Freis ED, Vidt DG, et al. (1988) Intravenous labetalol in the treatment of hypertension and hypertensive emergencies. Am J Med 62: 1062-1067. 